\title{
The effects of fashion product salesperson's emotional dissonance and emotional intelligence on prosocial behaviors \\ - Focused on the salesperson at the department store -
}

\author{
Kyungbok Lee and Myungsun Chung ${ }^{\dagger}$ \\ Dept. of Clothing \& Textiles/Human Echology Research Institute, Chonnam National University, Korea
패션제품 판매원의 감정부조화와 감정지능이 친사회적 행동에 미치는 영향 - 백화점 판매원을 중심으로 - \\ 이 경 복·정 명 선 ${ }^{\dagger}$ \\ 전남대학교 의류학과/전남대학교 생활과학연구소
}

\begin{abstract}
This research aimed to examine the effect of emotional dissonance and emotional intelligence on the prosocial behavior of fashion salespeople in department stores, and whether emotional intelligence mediates the relationship between emotional dissonance and prosocial behavior. Moreover, we aimed to suggest a method to improve the prosocial behavior of salespeople as a strategy to obtain a continuous competitive advantage in an increasingly competitive fashion distribution environment. This research was conducted through a questionnaire survey, and 345 responses were collected from department store salespeople for the final analysis. First, the analysis results showed that the emotional dissonance of salespeople arose from their dealings with their organization and with customers. Prosocial behavior was deduced to be a factor of the cooperation with coworker and extra-role customer service. The emotional intelligence was deduced to be a factor of the use of emotion, regulation of emotion, self-emotion appraisal, and others'emotion appraisal. Second, with a higher level of emotional dissonance against the organization, there was less cooperation with coworker, while a higher emotional dissonance against customers resulted in increased cooperation with coworker. Third, it appeared that with a higher level of emotional dissonance against the organization, there was a higher utilization of use of emotion, self-emotion appraisal, and others'emotion appraisal of emotional intelligence. Fourth, as the regulation of emotion, self-emotion appraisal, and use of emotion were higher, there was more cooperation with coworker, whereas an increase in the utilization of one's own emotion and emotional control resulted in a higher level of extra-role customer service. Finally, emotional intelligence has a significant mediating effect between emotional dissonance and prosocial behavior. The above results suggest that for department stores to improve the prosocial behavior of their sales staff requires the establishment of a method to enhance the emotional intelligence of the staff. The results also indicate that there is a need for department
\end{abstract}

\footnotetext{
Received 1 August 2014, revised 20 October 2014, accepted 22 October 2014.

${ }^{\dagger}$ Corresponding author (mschung@chonnam.ac.kr)

This is an Open Access article distributed under the terms of the Creative Commons Attribution Non-Commercial License (http://creativecommons.org/licenses/by-nc/3.0) which permits unrestricted non-commercial use, distribution, and reproduction in any medium, provided the original work is properly cited.
} 
stores to prepare a systemic tool to enable them to select people with a high degree of emotional intelligence when recruiting salespeople.

Keywords: emotional dissonance(감정부조화), emotional intelligence(감정지능), prosocial behavior(친사회적 행동)

\section{Introduction}

패션유통산업에서 백화점은 이제까지 대표적인 소매업태였다. 그러나 최근 TV홈쇼핑뿐만 아니라, 프리미엄 아울렛 등과 같은 다양한 구매채널이 등 장하면서 백화점의 입지는 날로 어려워지고 있다. 이처럼 백화점은 업태 내 경쟁에서 업태 간 경쟁으 로 유통경쟁이 심화되면서 그 입지가 더욱 불안해 져 가고 있다. The Korea Chamber of Commerce and Industry $(\mathrm{KCCI})$ 의 유통산업통계 자료에 의하면 우 리나라 주요 3사 백화점의 연간 매출 증감률이 2010 년 9.5\%, 2011년 $8.9 \%, 2012$ 년 $-0.3 \%$ 로 계속 감소 하고 있다(KCCI, 2013).

따라서 백화점은 이러한 내수부진을 극복하고, 경 쟁우위를 달성하기 위한 방안으로 판매원의 고객 응대 태도와 행동예절, 매장환경 및 편의시설을 개 선하는 등 고객 서비스 품질 향상에 더욱 심혈을 기울이고 있으며(Kim, 2013), 특히 인적서비스 즉 판매원이 제공하는 서비스 품질 향상에 초점을 두 고 있다(Kim et al., 2012). 예컨대, 백화점은 분기별 로 ‘모니터 요원' 또는'미스터리 쇼퍼’라는 암행고 객을 파견하여 판매원의 $\mathrm{CS}$ (Customer Service)를 평 가하게 한 후 그 평가를 인사고가에 반영하며, 특 히 낮은 평가를 받은 판매원에게는 일정기간동안 서비스 재교육을 시키고 있다(Park, 2013). 이러한 실태는 백화점 판매원들이 고객의 무리한 요구로 인해 화가 치밀어 오를 때조차 자신의 실제 감정을 숨기고 웃으면서 고객을 대해야 한다는 의미를 내 포하고 있다. 물론 판매원과 고객과의 직접적인 긍 정적 관계유지가 백화점의 판매목표 달성에 매우 중요한 요인이기 때문에, 판매원은 자신이 판매하 고 있는 제품이나 서비스에 관한 충분한 지식을 갖 춰야 함은 물론 자신의 서비스 역량을 최대한 발휘 하여 고객을 응대하는 것이 그들의 고유 업무임은 분명한 사실이다.
그러나 백화점이 판매원의 실제적인 내적 감정 을 고려하지 않고 기업차원의 성과만을 위해 지나 친 감정노동 수행을 요구할 경우, 판매원은 자신의 내적 감정과 기업이 요구하는 감정표현과의 상충 으로 인해 감정부조화를 경험할 수밖에 없을 것이 다. 실제로, 백화점 판매원들은 어떤 상황에서도 고 객에게 무조건 고개를 숙이게 만드는 회사의 방침 에 힘들어 하고 있으며, 판매원 4 명 중 1 명은 우울 증으로 심리 상담이나 치료를 필요로 하는 것으로 파악되었다(Cho, 2012). Spencer and Rupp(2009)는 감정노동자들이 고객으로부터 부당한 대우를 받고 있음을 인식하면서도 조직의 규범에 부합하기 위 해 참아가면서 감정노동을 수행하게 되면 결과적 으로 고객뿐만 아니라, 동료에게까지 부정적 행동 이 나타난다고 밝혔다.

한편, Wong and $\operatorname{Law}(2002)$ 는 감정의 조절능력 이 탁월한 조직구성원의 경우, 조직에 대한 헌신과 몰입의 정도가 높을 뿐만 아니라, 다른 구성원들과 도 긍정적인 관계를 형성함으로써 기업의 장기적 생산성을 높일 수 있다고 밝혔다. Lee and $\operatorname{Kim}(2012)$ 은 고객접점 종사원이 업무수행 중 고객의 불량행 동으로 인해 경험하게 되는 부정적 감정이 고객 또 는 조직구성원에게 도움을 주는 행동인 친사회적 행동을 감소시키지만, 자기감시성 및 자기통제성과 같은 개인의 기질적 특성이나 신념이 친사회적 행 동의 감소를 완화시킬 수 있다고 하였다.

지금까지 조직구성원의 감정관련 국내 연구들은 주로 경영학분야에서 수행되어져 왔으며, 조직구성 원의 감정관리 및 통제가 조직이나 기업차원의 성 과와 관련된 요인인 서비스 품질, 직무태도, 비과업 행동 등에 영향을 미친다는 것과 이러한 요인들의 영향력은 감정지능, 직무자율성, 사회적 지원 등에 의해 조절될 수 있다는 것을 밝혀왔다(Kim, 2008; Park, 2009; Park \& Woo, 2010). 최근 국내 의류학 분야에서도 감정관련 연구들이 보고되고 있으며, 
주로 판매원을 대상으로 하여 감정노동의 긍정적 측면인 직무만족, 성과 등에 영향을 주는 요인들과 감정노동의 부정적 측면인 탈진감, 이직의도 등에 영향을 주는 요인들을 밝혀왔다(Choo et al., 2010; Kang \& Lee, 2012; Lee \& Chung, 2008). Lee and $\operatorname{Kim}(2012)$ 은 이러한 연구들이 실제 판매원의 감정 노동에 대한 이해와 구체적인 실태파악을 결여하 고 있음을 지적하고, 판매원들의 감정노동 특성과 관련 변인들을 파악하고자 한 연구를 통해 감정노 동에 따른 감정부조화가 결국 감정소진에 영향을 미친다고 밝혔다. 그러나 이 연구에서도 이두 변인 들 간의 관계에 내재할 개연성이 있는 변인들은 다 루지 않았다. 더욱이 서비스 제공자가 조직이나 조 직의 다른 구성원에게 직접적으로 도움을 주는 행 동, 즉 친사회적 행동에 관심을 가진 연구는 백화 점 판매원에 대한 고객의 반응을 분석한 $\operatorname{Kim}(2010)$

의 연구를 제외하고는 아직 부족한 실정이다.

따라서 우리사회의 감정노동자들에 대한 학계 및 업계의 관심이 증가하고 있는 현 시점에서 한국 의 백화점들이 고객을 위한 서비스품질 향상이라 는 목표아래 판매원들에게 요구하고 있는 대 고객 친사회적 행동이 판매원들의 감정부조화를 야기할 것으로 유추되는바, 백화점 판매원들이 감정노동을 수행하는 과정에서 경험하는 감정부조화가 고객을 위한 친사회적 행동과 그들의 상사나 동료에 대한 친사회적 행동에 어떻게 반영되는가를 구체적으로 파악해 볼 필요성이 제기된다.

본 연구는 우선 백화점의 패션제품 판매원을 대 상으로 하여 그들이 직무수행 중 경험하게 되는 감 정부조화와 감정지능이 각각 고객과 조직에 대한 친사회적 행동에 영향을 미치는가와 감정부조화가 감정지능을 매개하여 대 고객 및 대 조직을 위한 친사회적 행동에 영향을 미치는가를 구명하고자 하였다.

\section{Background}

\section{Emotional dissonance}

감정부조화는 실제 감정과 조직의 규범에 따르는 감정이 충돌할 때 발생하며(Rafaeli \& Sutton, 1987), 조직상황에서의 감정부조화는 조직구성원들이 실
제로 느끼는 감정과 조직이 요구하는 감정 간의 갈 등으로 인해 경험하게 되는 불편한 느낌의 감정 상 태를 의미한다(Middleton, 1989). 그러나 Morris and Feldman(1996)은 본연의 감정이 아닌 것을 표현하 거나 혹은 지각된 원래의 감정을 억제하는 행동자 체를 감정부조화라 하였으며, 이를 조직의 목적과 표현규범에 따라 수행되는 감정노동의 한 구성 요 인으로 보았다. Van Dijk and Kirk-Brown(2006)은 감정부조화를 감정노동 수행 과정에서 자신의 순 순한 내적 감정과 조직이 표현규칙을 통해 요구하 는 감정표현내용이 서로 상충할 경우 경험하게 되 는 불편한 느낌이나 갈등상태로 정의하였다.

Abraham(1999)은 고객에게 인적서비스를 제공하 는 감정노동자의 경우, 직무특성상 고객 앞에서 긍 정적인 감정을 연기하거나 자신이 실제로 느끼는 부정적인 감정을 참아야 할 때 감정부조화를 경험 한다고 밝혔으며, $\operatorname{Kim}(2008)$ 은 판매원이 고객과의 상호작용 과정에서 이러한 감정부조화를 경험하게 되면 고객에 대한 도움행동을 감소시킨다고 하였 다. 또한 $\operatorname{Park}(2008)$ 은 조직이 요구하는 긍정적 감 정표현수준을 높게 지각한 감정노동자일수록 감정 부조화를 더 많이 경험하고, 이러한 감정부조화는 직무소진과 이직의향에 영향을 미친다고 밝히고, 감정노동자들이 감정노동을 수행하는 과정에서 감 정부조화 경험 유무가 그들의 직무 소진과 이직의 향을 증대시키는 주요 요인이라고 하였다. 그러나 Humphrey, Pollack, and Hawver(2008)은 서비스직에 종사하는 감정노동자의 경우, 직무를 효과적으로 수행하기 위해서는 조직내 구성원과의 상호작용 과 정에서도 조직이 요구하는 감정을 표현하기 위해 노력하고 있다고 밝혔다.

이상과 같은 선행연구 고찰을 통해 조직내 구성 원 중 판매원이 경험하는 감정부조화는 고객과의 상호작용 과정에서 경험할 뿐 아니라, 조직구성원 과의 상호작용 과정에서도 경험할 가능이 있음을 유추할 수 있다. 따라서 본 연구에서는 백화점의 패션제품 판매원이 현장에서 경험하는 감정부조화 를 대고객과 대조직 모두를 포함하였다.

한편, Giardini and Frese(2006)는 판매원이 직무 를 수행하는 과정에서 감정부조화를 경험하더라도 그 들의 심리적 자원이라 할 수 있는 감정능력(emotion 
competence)이 이러한 불편한 느낌을 완화시켜줄 가능성이 크다고 밝혔다. 또한 $\operatorname{Park(2009)ㅇㅡㄴ~ㅇㅣㄹㅓㅎㅏㄴ~}$ 감정부조화가 직무만족, 조직몰입 및 이직의향에 미치는 부정적 영향은 상사나 동료로부터의 업무 수행과 관련된 협력과 도움, 즉 사회적 지원에 의 해 완화된다고 밝혔다.

\section{Emotional intelligence}

감정지능이란 자신과 타인의 감정을 잘 인식하 고, 다양한 종류의 감정들을 잘 구분하여 이를 토대 로 자신의 사고와 행동의 방향을 도출해내는 능력 을 말한다(Salovey \& Mayer, 1990). Goleman(1995) 은 이러한 감정지능이 성인들의 직장생활에서의 성공을 효과적으로 예측해 줄 수 있는 지표가 될 수 있다고 보았고, 이러한 관점에서 조직구성원의 감정지능을 개발하기 위한 적절한 교육과 관리가 중요하다고 강조하였다.

Wong and Law(2002)는 기존의 문헌고찰을 토대 로 감정지능을 실제로 측정할 수 있는 척도를 개발 하였으며, 감정지능이 자기감정인식, 타인감정인식, 자기감정조절, 자기감정활용이라는 4 개 차원으로 구 성된다고 밝혔다. 자기감정인식 차원은 자신의 감 정을 이해하고, 그것을 표현할 수 있는 능력을 의 미하고, 타인감정인식 차원은 다른 사람의 감정을 지각하고 이해하는 능력을 의미한다. 자기감정조절 차원은 당면한 심리적 고통으로부터 신속하게 벗 어날 수 있도록 자신의 감정을 조절하는 능력을, 마지막으로, 자기감정활용 차원은 건설적인 활동과 개인의 성과달성을 지향할 수 있도록 자신의 감정 을 활용할 줄 아는 능력을 의미한다. 이들은 또한 조직구성원의 감정지능이 그들의 직무성과와 직무 태도에 영향을 미치며, 특히 상사의 감정지능은 부 하직원의 직무만족뿐만 아니라, 규정 이상의 역할 행동에도 영향을 미친다고 밝혔다. Park and Yoo(2006) 는 Wong and Law(2002)가 개발한 감정지능 척도를 국내기업에 종사하는 조직구성원의 감정지능과 직 무태도에 관한 연구에 적용하였으며, 이들 또한 감 정지능이 자기감정인식, 타인감정인식, 자기감정조 절 및 자기감정활용으로 구분되었고, 조직구성원 중 상사의 감정지능이 부하직원의 직무만족과 업 무수행에 영향을 미친다고 밝혔다. Jung and Kim
(2006) 또한 조직구성원의 감정지능과 그들의 업무 수행 능력과 관련된 혁신행동에 관한 연구에서 감 정지능이 자기감정인식, 타인감정인식, 자기감정조 절, 자기감정활용이라는 4 개 차원으로 구분된다고 하였으며, 감정지능의 모든 요인들이 각각 혁신적 행동에 영향을 미친다고 밝혔다.

다른 한편, $\operatorname{Kim}(2008)$ 은 판매원이 판매과정에서 경험하는 부정적 감정이 판매원의 주관적 행복과 고객 지향적 판매행동에 부정적 영향을 미친다고 밝혔으며, 감정지능이 이러한 부정적 영향을 완화 시켜준다고 하였다. Shin, Han, Kim, and $\operatorname{Kim}(2008)$ 은 감정노동자를 대상으로 그들의 감정지능에 따 른 감정노동이 직무탈진과 직무열의에 미치는 영 향에 관한 연구에서 감정노동자들이 강도 높은 감 정노동을 수행하더라도 그들의 감정지능이 높을 경우, 직무열의의 정도가 높아진다고 밝혔다. Ryu and Yoo(2008)는 상사의 리더십이 부하의 혁신행 동에 미치는 영향에 관한 연구에서 상사의 리더십 이 부하의 혁신행동에 미치는 직접적인 영향보다 상사의 감성지능을 매개하여 미치는 영향이 더 크 다고 밝혔다. Park and $\mathrm{Woo}(2010)$ 는 특히 고객접점 에서 서비스를 제공하는 종사원들의 경우, 감정노 동수행 후 경험하는 감정부조화는 대인관계 일탈 과 조직일탈을 포함하는 반생산적 행동에 영향을 미치며, 이 때 사원들의 감정지능 차원들 중 타인 감정인식과 자기감정조절 차원이 이 영향관계를 완화시켜 준다고 밝혔다.

\section{Prosocial behavior}

친사회적 행동이란 일반적으로 다른 사람에게 직접 적으로 도움을 주는 행동을 말하며(Brief \& Motowidlo, 1986), 조직차원에서 친사회적 행동은 서비스 제공 자가 조직이나 조직의 다른 구성원들에게 직접적 으로 도움을 주는 행동 또는 서비스 제공자가 개인 또는 조직의 직접적인 이익을 촉진하기 위한 역할 과 의도로 정의된다(Bettencourt \& Brown, 1997).

Bettencourt and Brown(1997)은 서비스 제공자 측면에서의 친사회적 행동은 규정된 고객서비스, 규정 이상의 고객서비스 및 협력이라는 3 개 차원으 로 구성된다고 밝혔다. 규정된 고객서비스 차원은 서비스 제공자가 해야 하는 기대된 행동을 의미하 
고, 규정 이상의 고객서비스 차원은 공식적인 역할 요구 이상으로 고객에게 서비스를 제공하는 것을 의미하며, 협력은 조직의 목표달성을 위하여 다른 구성원을 도와주는 것을 의미한다. 이들은 또한 규 정된 고객서비스 차원과 규정 이상의 고객서비스 차원이 고객만족과 우호적 구전 등 서비스에 대한 고객들의 평가에 영향을 미치며, 직장 내 공정성과 직무만족이 친사회적 행동에 영향을 미친다고 밝 혔다. Lee(2001)는 고객접점에서의 서비스 제공자 의 친사회적 행동은 규정된 고객서비스와 규정 이 상의 고객서비스로만 구성되며, 규정된 고객서비스 는 고객 애호도에, 규정 이상의 고객서비스는 고객 들의 참여와 협조 등 고객의 자발적 행동에 영향을 미친다고 밝혔다. Yoon and Park(2005)은 고객접점 에서의 서비스 제공자의 친사회적 행동을 다룬 연 구에서 규정 이상의 고객서비스 행동은 서비스 제 공자의 내적 동기부여의 영향을 받는다고 하였다. 즉, 서비스 제공자가 직무수행에 있어서 자신의 업 무처리 능력이나 영향력을 높게 인지할수록 조직 구성원 및 고객과 더 우호적인 관계를 유지한다는 것이다. Lee and Lee(2006)는 항공사 종사원의 친사 회적 행동을 종사원 스스로 평가하게 한 연구에서 종사원의 내적 심리상태인 심리적 임파워먼트가 직 무만족과 조직몰입을 매개하여 친사회적 행동의 규정 이상의 고객서비스 차원과 협력 차원에 영향 을 미친다고 밝혔다.

Park, Nam, and Lee(2002)는 서비스접점에서의 종사원의 태도 및 행동이 고객의 서비스품질 평가 에 직접적으로 영향을 미치기 때문에, 종사원의 친 사회적 행동이 중요하다는 것을 강조하였으며, 기 업이 다양한 서비스 훈련과 함께 권한을 부여함으 로써 종사원들의 직무만족을 증가시킨다면 그들의 친사회적 행동 또한 증가할 것이라고 하였다. Lee, Park, and Kwon(2010)은 또한 조직구성원이 조직에 대한 강한 소속감과 다른 조직원들과의 긍정적 유 대감과 같은 조직응집성을 높게 지각할수록 친사 회적 행동을 더 많이 한다고 밝혔다.

이상과 같은 고찰을 통해 백화점의 패션제품 판 매원이 감정노동을 수행하면서 경험하는 감정부조 화가 대 고객 및 대 조직을 위한 친사회적 행동에 부정적 영향을 미칠 것이고, 판매원의 감정지능, 자
기감시성, 자기통제성 등이 부정적 영향을 완화시 킬 수 있을 것으로 유추할 수 있다. 예컨대, 백화점 판매원의 감정지능, 자기감시성 및 자기통제성 등 이 높을수록 고객의 감정을 더 잘 이해하고, 자기 감정을 조절하여 더 나은 대 고객 서비스를 제공할 것이고, 이는 고객 만족과 아울러 판매원 자신의 긍정적인 감정을 증진시킴으로써 다른 조직구성원 을 위한 친사회적 행동에 긍정적인 영향을 미칠 것 으로 예측된다. 특히 패션제품은 다른 제품들과 달 리 개인의 신체와 밀접하게 관련된 감성적인 제품 이라는 점에서 판매원이 고객의 까다로운 요구나 행동에 직면하기 쉽고, 한국의 백화점에서 취급하 는 대부분의 패션브랜드가 백화점 직영이 아닌 중 간관리 체재로 운영되고 있어 백화점 패션제품 판 매원은 패션제조업체와 백화점이라는 두 개의 조 직의 규제를 받아야 한다는 점에서 여타의 판매원 들보다 더 많은 감정부조화를 경험할 개연성이 더 높을 것으로 예측할 수 있다.

따라서 본 연구에서는 우선 백화점의 패션제품 판매원의 대 고객 및 대 조직 친사회적 행동에 미 치는 감정부조화의 영향과 감정지능의 영향 및 감 정부조화가 감정지능을 매개하여 친사회적 행동에 미치는 영향을 파악하기 위해 아래와 같은 연구가 설을 설정하였다.

\section{Methods}

\section{Research hypothesis}

가설 1: 판매원의 감정부조화는 친사회적 행동 에 영향을 미칠 것이다.

가설 2: 판매원의 감정부조화는 감정지능에 영 향을 미칠 것이다.

가설 3: 판매원의 감정지능은 친사회적 행동에 영향을 미칠 것이다.

가설 4: 판매원의 감정부조화는 감정지능을 매 개하여 친사회적 행동에 영향을 미칠 것이다.

\section{Measurements}

본 연구에서 친사회적 행동은 백화점 패션제품 판매원이 고객 및 다른 조직구성원들에게 도움이 되는 역할을 수행하려는 의도와 행동을 의미하며, 
이를 측정하기 위해 Bettencourt and Browm(1997) 의 연구에서 사용된 문항들 중 협력과 규정 이상의 고객서비스 차원의 문항들만을 본 연구에 맞게 수 정 - 보완한 총 10 문항을 5 점 척도(1점: 전혀 그렇 지 않다 5점: 매우 그렇다)로 제시하였다. 감정부 조화는 감정노동 수행 중 자신의 순수한 내적 감정 과 조직이 요구하는 감정표현이 서로 상충할 경우 경험하게 되는 불편한 느낌을 의미하며, 이를 측정 하기 위해 Van Dijk and Kirk-Brown(2006), Park(2009) 의 연구에서 사용되었던 문항들을 참고하여 백화 점이라는 유통채널의 조직특성과 판매원의 직무상 황에 맞도록 재구성한 총 8 문항을 5 점 척도로 제시 하였다. 감정지능은 자신과 타인의 감정을 잘 인식 하고, 다양한 종류의 감정들을 잘 구분하여 자신의 사고와 행동의 방향을 도출해내는 능력을 의미하 며, 이를 측정하기 위해 Wong and Law(2002)가 개 발한 WLEIS(Wong and Law Emotional Intelligence Scale)을 토대로 하여 구성한 총 16 문항을 5점 척도 로 제시하였다.

기타 판매원의 인구통계적 특성인 성별, 연령, 결 혼 여부, 급여, 근무기간 및 근무시간을 파악하였다.

\section{Data collection and analysis}

본 연구에서는 전라남북도에 소재한 $\mathrm{L}$ 백화점과 $\mathrm{S}$ 백화점 내 '의류, 화장품, 신발 및 피혁, 액세서리' 부문에서 상품을 판매하고 있는 판매원을 연구대 상으로 선정하였다. 연구대상을 패션제품을 판매하 는 2 개의 백화점 판매원으로 한정한 이유는 백화점 의 조직구조, 직무환경 및 교육 시스템이 할인점, 전문점 등 타 소매업체와 다르고, 판매원에게 요구 하는 책임과 판매원의 역할이 백화점들 간 유사한 것으로 파악되었기 때문이다. 본 조사를 실시하기 전 1·2차 예비조사를 하였으며, 1차 예비조사는 약 10 명의 판매원들과의 인터뷰를 통해 판매원이 고 객을 대할 때의 감정표현 방식과 업무활동으로 인 해 판매원이 경험한 스트레스에 대해 조사하였다. 1 차 예비조사에서 수집된 자료를 토대로 제작한 질 문지를 이용하여 백화점에서 패션제품을 판매하는 판매원 100 명을 대상으로 2 차 예비조사를 실시하 였으며, 조사결과, 신뢰도가 낮은 문항을 제외하고, 중복되거나 이중적인 의미를 가지는 것으로 파악
된 문항은 수정-보완한 후, 본 조사를 위한 질문지 를 구성하였다. 본 조사는 2013년 11월 8일부터 11 월 26일까지 예비조사와 같은 조건의 판매원 400 명 을 대상으로 실시하였으며, 회수된 질문지 중 응답 이 불완전한 것을 제외한 345 부를 최종분석에 이용 하였다. 응답자들 중 남성이 81 명(23.5\%), 여성이 264 명 $(76.5 \%)$ 이었으며, 연령대는 20 대 150 명 $(43.5 \%)$, 30 대 137 명 $(39.7 \%), 40$ 대 이상이 58 명 $(16.8 \%)$ 인 것 으로 파악되었다. 동일 백화점 근무기간은 1 3년 미만 129명(37.4\%), 3 5년 미만 137명(39.7\%), 5 10 년 미만 73 명(21.2\%), 10 년 이상이 80 명(23.2\%)인 것으로 나타났다.

수집된 자료 분석을 위해 SPSS 21.0을 이용하였 으며, 연구가설 검증을 위해 빈도분석, 요인분석, 신 뢰도분석(Cronbach's $\alpha$ ), 회귀분석 및 경로분석을 실시하였다.

\section{Results and Discussion}

\section{The effect of emotional dissonances on} prosocial behaviors

판매원의 감정부조화가 친사회적 행동에 영향을 미칠 것이라는 가설 1 을 검증하기 위해, 먼저 판매 원이 현장에서 경험하는 감정부조화의 개념적 차 원과 친사회적 행동의 개념적 차원을 분류하였다.

1) Factor analysis of emotional dissonances 감정부조화에 관한 8 문항을 Varimax 회전법을 이용하여 주성분 요인분석을 실시한 결과, 〈Table $1>$ 과 같이 고유치 1.0 이상의 2 개 요인이 도출되었 다. 2 개 요인의 신뢰도계수는 각각 $.93, .89$ 로 파악되 었으며, 두 요인이 설명한 총 변량은 $78.59 \%$ 이었다.

요인 1은 판매원이 직장상사 혹은 동료를 대할 때 실제 느끼는 감정을 그대로 표현할 수가 없어 힘들다거나 표현하는 감정과 실제 감정 간의 차이 로 인해 혼란스러움을 경험한다는 문항 등이 포함 되었기 때문에“대조직 감정부조화”로 명명하였고, 요인 2는 판매원이 고객을 대할 때 그들의 실제 감 정을 숨기고 고객이 원하는 긍정적인 감정을 표현 하려고 노력한다는 문항 등이 포함되었기 때문에 "대고객 감정부조화"로 명명하였다. 
$\langle$ Table 1〉 Factor loadings of emotional dissonances

\begin{tabular}{|c|c|c|c|c|}
\hline Items & $\begin{array}{l}\text { Factor } \\
\text { loading }\end{array}$ & $\begin{array}{c}\text { Eigen- } \\
\text { value }\end{array}$ & $\begin{array}{c}\% \text { of variance } \\
(\% \text { of } \\
\text { cumulative } \\
\text { variance })\end{array}$ & $\begin{array}{c}\text { Cronbach's } \\
\alpha\end{array}$ \\
\hline Factor 1: Organization & & \multirow{5}{*}{4.93} & \multirow{5}{*}{$\begin{array}{l}61.66 \\
(61.66)\end{array}$} & \multirow{5}{*}{.93} \\
\hline $\begin{array}{l}\text { - It is difficult when I show the supervisor or coworker does not match what } \\
\text { I really feel. }\end{array}$ & .90 & & & \\
\hline $\begin{array}{l}\text { - It is uncomfortable with supervisor or coworker at work when I can't } \\
\text { express what I really feel. }\end{array}$ & .88 & & & \\
\hline $\begin{array}{l}\text { I felt a conflict when I show feeling to supervisor or coworker that are } \\
\text { different from what I feel inside. }\end{array}$ & .86 & & & \\
\hline $\begin{array}{l}\text { - It is confusing for me not to display real feelings to the supervisor or } \\
\text { coworker. }\end{array}$ & .82 & & & \\
\hline \multicolumn{4}{|l|}{ Factor 2: Customer } & \multirow{5}{*}{.89} \\
\hline $\begin{array}{l}\text { - It is uncomfortable with customers at work when I can't express what I } \\
\text { really feel. }\end{array}$ & .87 & \multirow{4}{*}{1.35} & \multirow{4}{*}{$\begin{array}{c}16.93 \\
(78.59)\end{array}$} & \\
\hline - It is difficult when I show the customer does not match what I really feel. & .83 & & & \\
\hline $\begin{array}{l}\text { - I felt a conflict when I show feeling to customers that are different from } \\
\text { what I feel inside. }\end{array}$ & .80 & & & \\
\hline $\begin{array}{l}\text { - It is confusing for me not to display real feelings to the customers when } \\
\text { I working. }\end{array}$ & .79 & & & \\
\hline
\end{tabular}

2) Factor analysis of prosocial behaviors

친사회적 행동에 관한 10 문항을 Varimax 회전법 을 이용하여 주성분 요인분석을 실시한 결과, 2 문 항이 설명력과 신뢰도를 저해시키는 것으로 나타 나, 이 문항들을 제외한 나머지 8 문항을 재분석하
였다. 그 결과, 〈Table 2$\rangle$ 와 같이 고유치 1.0 이상의 2개 요인이 도출되었고, 2개 요인의 신뢰도계수는 각각 $.89, .84$ 로 파악되었으며, 이 두 요인이 설명한 총 변량은 $72.16 \%$ 이었다.

요인 1은 판매원이 업무 수행 중 업무량이 많은

$\langle$ Table 2〉 Factor loadings of prosocial behaviors

\begin{tabular}{|c|c|c|c|c|}
\hline Items & $\begin{array}{l}\text { Factor } \\
\text { loading }\end{array}$ & $\begin{array}{l}\text { Eigen- } \\
\text { value }\end{array}$ & $\begin{array}{c}\% \text { of variance } \\
(\% \text { of } \\
\text { cumulative } \\
\text { variance })\end{array}$ & $\begin{array}{c}\text { Cronbach's } \\
\alpha\end{array}$ \\
\hline $\begin{array}{l}\text { Factor 1: Cooperation with coworker } \\
\text { - Helps other employees who have heavy work loads. } \\
\text { - Voluntarily gives of his/her time to help other employees. } \\
\text { - Is always ready to lend a helping hand to those employees around him/her. } \\
\text { - Willingly helps other who have work related problems. }\end{array}$ & $\begin{array}{l}.86 \\
.85 \\
.82 \\
.82\end{array}$ & 4.37 & $\begin{array}{c}54.59 \\
(54.59)\end{array}$ & .89 \\
\hline $\begin{array}{l}\text { Factor 2: Extra-role customer service } \\
\text { - Voluntarily assists customers even if it means going beyond job requirements. } \\
\text { - Often goes above and beyond the call of duty when serving customers. } \\
\text { - Help customers with problems beyond what is expected or required. } \\
\text { - Frequently goes out the way to help a customer. }\end{array}$ & $\begin{array}{l}.85 \\
.81 \\
.79 \\
.72\end{array}$ & 1.41 & $\begin{array}{c}17.57 \\
(72.16)\end{array}$ & .84 \\
\hline
\end{tabular}


직장 동료를 도와주려고 노력하고, 직장 동료를 돕기 위해 기꺼이 시간을 할애할 마음이 있다는 문항 등이 포함되었기 때문에 “동료와의 협력"으 로 명명하였고, 요인 2 는 판매원이 고객을 대할 때 고객이 규정된 이상의 요구를 하더라도 고객을 돕 기 위해 노력하고, 고객이 기대하는 것 이상의 서 비스를 제공하기 위해 노력한다는 문항 등이 포함 되었기 때문에 “규정 이상의 고객서비스"로 명명 하였다.

이러한 결과는 항공사 종사원을 대상으로 친사 회적 행동에 관한 연구에서 친사회적 행동을 협조 와 규정 이상의 고객서비스로 분류한 Lee and Lee (2006)의 연구결과와 일치한다.

3) The effect of emotional dissonances on prosocial behaviors

판매원의 감정부조화가 친사회적 행동에 영향을 미치는가를 파악하기 위해 감정부조화를 독립변인 으로, 친사회적 행동을 종속변인으로 하여 회귀분 석을 실시한 결과는 〈Table 3〉과 같이 나타났다. 감 정부조화가 전체적으로 친사회적 행동의 동료와의 협력 $(F=9.18, p<.001)$ 차원과 규정 이상의 고객서비 스 $(F=3.23, p<.05)$ 차원에 통계적으로 유의한 영향 을 미치는 것으로 나타났고, 이것이 동료와의 협력 차원과 규정 이상의 고객서비스 차원을 설명한 총 변량은 각각 $5 \%, 2 \%$ 인 것으로 나타났다.

그러나 차원별 감정부조화가 차원별 친사회적 행 동에 미치는 영향을 살펴보면, 대조직 감정부조화 가 높을수록 친사회적 행동의 동료와의 협력 $(\beta=$ $-.27, t=-4.24, P<.001)$ 은 낮은 것으로 나타난 반 면, 대고객 감정부조화가 높을수록 동료와의 협력 $(\beta=.19, t=2.95, P<.01)$ 은 높아지는 것으로 나타났
다. 이는 판매원이 동료나 상사로 인해 감정부조화 를 경험하게 되면 직무수행 중 그들이 도움을 필요 로 할 때 자발적으로 도와주려하지 않으나, 판매원 이 고객과의 상호작용에서 감정부조화를 경험했을 때에는 도움을 필요로 하는 동료나 상사에게 자발 적으로 도움을 제공한다는 것을 의미한다.

한편, 감정부조화 두 차원 모두 친사회적 행동의 규정 이상의 고객서비스에는 통계적으로 유의한 영향을 미치지 않았으나, 이들의 관계가 부적인 것 으로 나타난 결과는 판매원이 상사나 동료 및 고객 으로 인해 감정부조화를 경험하게 되면 대고객 서 비스 접점 시 고객을 위한 도움행동이 감소할 경향 이 있다는 것으로 해석된다.

이와 같은 결과는 고객접점 서비스를 수행하는 종사원이 서비스 접점 시 고객으로부터 부정적 감 정을 많이 경험할수록 고객에 대한 친사회적 행동 을 덜 한다고 밝힌 Lee and Kim(2012)의 연구결과 와 유사하다. 그러나 고객으로 인한 감정부조화를 경험하더라도 동료나 상사를 위한 자발적인 도움 행동을 한다는 결과가 주시되며, 이는 대부분의 판 매원들이 상사나 동료 및 고객을 독립적으로 지각 한다는 것과 조직구성원 모두가 목표달성을 위해 서는 서로에게 도움을 제공해야 하는 입장이라는 동류의식 때문인 것으로 해석된다. 결과적으로 판 매원의 감정부조화가 친사회적 행동에 영향을 미 칠 것이라는 가설 1 은 부분적으로 지지되었다.

\section{The effect of emotional dissonances on} emotional intelligences

판매원의 감정부조화가 감정지능에 영향을 미칠 것이라는 가설 2 를 검증하기 위해 먼저, 감정지능 의 개념적 차원을 분류하였다.

$\langle$ Table 3〉 The effect of emotional dissonances on prosocial behaviors

\begin{tabular}{|c|c|c|c|c|c|c|c|}
\hline Dependent variables & Independent variables & B & $\begin{array}{c}\text { Standard } \\
\text { error }\end{array}$ & $\beta$ & $t$-value & $F$ & $R^{2}$ \\
\hline \multirow{2}{*}{$\begin{array}{c}\text { Cooperation } \\
\text { with coworker }\end{array}$} & Organization & -.19 & .05 & -.27 & $-4.24 * * *$ & \multirow{2}{*}{$9.18 * * *$} & \multirow{2}{*}{.05} \\
\hline & Customer & .13 & .04 & .19 & $2.95 * *$ & & \\
\hline \multirow{2}{*}{$\begin{array}{c}\text { Extra-role } \\
\text { customer service }\end{array}$} & Organization & -.03 & .05 & -.04 & -.64 & \multirow{2}{*}{$3.23 *$} & \multirow{2}{*}{.02} \\
\hline & Customer & -.08 & .05 & -.11 & -1.65 & & \\
\hline
\end{tabular}

${ }^{*} p<.05, * * p<.01, * * * p<.001$ 
1) Factor analysis of emotional intelligences

감정지능에 관한 16 문항을 Varimax 회전법을 이 용하여 주성분 요인분석을 실시한 결과, 2 문항이 설명력과 신뢰도를 저해시키는 것으로 나타나, 이 문항을 제외한 나머지 14 문항을 재분석하였다. 분 석 결과, 〈Table 4〉와 같이 고유치 1 이상인 4 개의 요인이 도출되었고, 4 개 요인의 신뢰도계수는 각각 $.90, .89, .88, .73$ 으로 파악되었으며, 이 요인들이 설 명한 총 변량은 $76.84 \%$ 였다.

요인 1 은 판매원이 자신을 능력 있는 사람이라 고 스스로 일깨우고, 목표를 설정한 후 그것을 성 취하기 위해 최선을 다한다는 문항 등이 포함되었 기 때문에 “자기감정활용”이라 명명하였고, 요인 2 는 판매원이 자신의 감정을 잘 통제할 수 있고, 화 가 났을 때에도 재빨리 평온을 찾을 수 있다는 문 항 등이 포함되었기 때문에 “자기감정조절”로 명명 하였다. 요인 3 은 판매원이 자신의 감정을 잘 이해
하고 있고, 자신이 왜 특정한 감정을 갖게 되는지 를 잘 알고 있다는 문항 등이 포함되었기 때문에 “자기감정인식"으로 명명하였고, 요인 4는 판매원 이 다른 사람들의 감정을 잘 감지하고, 동료들의 행동을 보고 그들의 감정 상태를 알 수 있다는 문 항 등이 포함되었기 때문에 “타인감정인식”으로 명 명하였다.

이러한 결과는 조직 구성원의 감정지능이 직무 성과와 직무태도에 미치는 영향에 관한 연구에서 감정지능을 자기감정활용, 자기감정조절, 자기감정 인식, 타인감정인식이라는 4 개 차원으로 분류한 Wong and Law(2002)의 연구결과와 일치한다.

2) The effect of emotional dissonance on emotional intelligence

판매원의 감정부조화가 감정지능에 영향을 미치 는가를 파악하기 위해 감정부조화를 독립변인으로,

$\langle$ Table 4〉 Factor loadings of emotional intelligences

\begin{tabular}{|c|c|c|c|c|}
\hline Items & $\begin{array}{c}\text { Factor } \\
\text { loading }\end{array}$ & $\begin{array}{l}\text { Eigen- } \\
\text { value }\end{array}$ & $\begin{array}{c}\% \text { of variance } \\
(\% \text { of } \\
\text { cumulative } \\
\text { variance })\end{array}$ & $\begin{array}{c}\text { Cronbach's } \\
\text { a }\end{array}$ \\
\hline $\begin{array}{l}\text { Factor 1: Use of emotion } \\
\cdot \text { I am a self-motivated person. } \\
\cdot \text { I always tell myself I am a competent person. } \\
\cdot \text { I would always encourage myself to try my best. } \\
\cdot \text { I always set goals for myself and then try my best to achieve them. }\end{array}$ & $\begin{array}{l}.90 \\
.86 \\
.79 \\
.64\end{array}$ & 6.40 & $\begin{array}{c}45.74 \\
(45.74)\end{array}$ & .90 \\
\hline $\begin{array}{l}\text { Factor 2: Regulation of emotion } \\
\text { - I am quite capable of controlling my own emotions. } \\
\text { - I can always calm down quickly when I am very angry. } \\
\text { - I have good control of my own emotions. } \\
\text { - I am able to control my temper and handle difficulties rationally. }\end{array}$ & $\begin{array}{l}.85 \\
.84 \\
.81 \\
.75\end{array}$ & 1.73 & $\begin{array}{c}12.33 \\
(58.07)\end{array}$ & .89 \\
\hline $\begin{array}{l}\text { Factor 3: Self-emotion appraisal } \\
\text { - I have good understanding of my own emotion. } \\
\text { - I have a good sense of why I have certain feelings most of the time. } \\
\text { - I really understand what I feel. }\end{array}$ & $\begin{array}{l}.88 \\
.87 \\
.82\end{array}$ & 1.51 & $\begin{array}{c}10.82 \\
(68.88)\end{array}$ & .88 \\
\hline $\begin{array}{l}\text { Factor 4: Others'emotion appraisal } \\
\text { - I am sensitive to the feelings and emotion of other. } \\
\text { - I am a good observer of others' emotions. } \\
\text { - I always know my coworkers emotions from their behavior. }\end{array}$ & $\begin{array}{l}.85 \\
.72 \\
.69\end{array}$ & 1.11 & $\begin{array}{c}7.96 \\
(76.84)\end{array}$ & .73 \\
\hline
\end{tabular}


$\langle$ Table 5〉 The effect of emotional dissonances on emotional intelligences

\begin{tabular}{|c|c|c|c|c|c|c|c|}
\hline Dependent variables & Independent variables & B & $\begin{array}{c}\text { Standard } \\
\text { error }\end{array}$ & $\beta$ & $t$ & $F$ & $R^{2}$ \\
\hline \multirow{2}{*}{ Use of emotion } & Organization & -.19 & .06 & -.22 & $-3.49 * * *$ & \multirow{2}{*}{$13.44 * * *$} & \multirow{2}{*}{.07} \\
\hline & Customer & -.06 & .05 & -.07 & -1.15 & & \\
\hline \multirow{2}{*}{ Others'emotion appraisal } & Organization & -.19 & .05 & -.24 & $-3.71 * * *$ & \multirow{2}{*}{$9.23 * * *$} & \multirow{2}{*}{.05} \\
\hline & Customer & .02 & .05 & .02 & .35 & & \\
\hline \multirow{2}{*}{ Self-emotion appraisal } & Organization & -.14 & .05 & -.20 & $-3.00 * *$ & \multirow{2}{*}{$4.89 * *$} & \multirow{2}{*}{.03} \\
\hline & Customer & .04 & .05 & .06 & .98 & & \\
\hline \multirow{2}{*}{ Regulation of emotion } & Organization & -.06 & .05 & -.08 & -1.18 & \multirow{2}{*}{$4.19^{*}$} & \multirow{2}{*}{.02} \\
\hline & Customer & -.08 & .05 & -.10 & -1.49 & & \\
\hline
\end{tabular}

${ }^{*} p<.05, * * p<.01, * * * p<.001$

감정지능을 종속변인으로 하여 회귀분석을 실시한 결과는 〈Table 5〉와 같이 나타났다. 감정부조화가 전 체적으로 감정지능의 자기감정활용 $(F=13.44 p<.001)$ 차원, 타인감정인식 $(F=9.23 p<.001)$ 차원, 자기감정 인식 $(F=4.89 p<.01)$ 차원, 자기감정조절 $(F=4.19 p<.05)$ 차원에 통계적으로 유의한 영향을 미치는 것으로 나타났고, 이것이 감정지능의 각 차원을 설명한 총 변량은 각각 $7 \%, 5 \%, 3 \%, 2 \%$ 인 것으로 나타났다.

그러나 차원별 감정부조화가 차원별 감정지능에 미치는 영향을 살펴보면, 대조직 감정부조화가 높 을수록 감정지능의 자기감정활용 $(\beta=-.22, t=-3.49$, $P<.001)$, 타인감정인식 $(\beta=-.24, t=-3.71, P<.001)$, 자기감정인식 $(\beta=-.20, t=-3.00, P<.01)$ 이 각각 낮 은 것으로 나타난 반면, 대고객 감정부조화는 감정 지능의 어떠한 차원에도 통계적으로 유의한 영향 을 미치지 않은 것으로 나타났다. 이러한 결과들은 판매원이 직무수행 중 상사나 동료로 인해 감정부 조화를 많이 경험할수록 자신이 능력 있는 사람이 라고 일깨우고, 목표성취를 위해 최선을 다하며, 자 신이 왜 특정한 감정을 갖게 되는가를 잘 이해하고, 다른 사람들의 행동을 통해 그들의 감정 상태를 잘 파악할 수 있는 능력을 잘 발휘하지 못한다는 것을 의미한다. 한편, 판매원이 고객에게 실제 감정을 표 현하지 못하고, 그로 인해 겪게 되는 어려움, 혼란 혹은 갈등은 그들의 감정지능에는 영향을 미치지 않는다는 것을 의미하며, 이는 고객에게 제품을 판 매하고, 필요한 서비스를 제공하는 것이 판매원의 주 업무이기 때문으로 해석된다. 그러나 대고객 감
정부조화가 감정지능의 자기감정활용과 자기감정 조절에 통계적으로 유의한 영향을 미치지 않았으 나, 대고객 감정부조화가 높을수록 자기감정활용과 자기감정조절이 낮아지는 경향이 있는 것으로 나 타난 결과가 주시되며, 이는 판매원이 고객을 응대 하는 과정에서 감정부조화를 경험하게 되면 자신 의 감정을 잘 다스리지 못하고, 처한 상황을 이성 적으로 처리할 수 있는 능력을 발휘하지 못할 개연 성이 있음을 유추하게 한다.

결과적으로, 판매원의 감정부조화는 감정지능에 영향을 미칠 것이라는 가설 2 는 부분적으로 지지되 었다.

\section{The effect of emotional intelligences on} prosocial behaviors

판매원의 감정지능이 친사회적 행동에 영향을 미칠 것이라는 가설 3 을 검증하기 위해 감정지능을 독립변인으로, 친사회적 행동을 종속변인으로 하여 회귀분석을 실시한 결과는 〈Table 6〉과 같이 나타났 다. 감정지능이 전체적으로 친사회적 행동의 동료 와의 협력 $(F=26.22, p<.001)$ 차원과 규정 이상의 고 객서비스 $(F=20.43, p<.001)$ 차원에 통계적으로 유의 한 영향을 미치는 것으로 나타났고, 이것이 동료와 의 협력 차원과 규정 이상의 고객서비스 차원을 설 명한 총 변량은 각각 $24 \%, 19 \%$ 인 것으로 나타났다. 판매원의 차원별 감정지능이 차원별 친사회적 행동에 미치는 영향을 살펴보면, 먼저 감정지능의 자기감정조절 $(\beta=.24, t=4.07, P<.001)$, 자기감정인식 
$\langle$ Table 6〉 The effect of emotional intelligences on prosocial behaviors

\begin{tabular}{|c|c|c|c|c|c|c|c|}
\hline Dependent variables & Independent variables & B & $\begin{array}{l}\text { Standard } \\
\text { error }\end{array}$ & $\beta$ & $t$-value & $F$ & $R^{2}$ \\
\hline \multirow{4}{*}{$\begin{array}{c}\text { Cooperation } \\
\text { with coworker }\end{array}$} & Use of emotion & .11 & .05 & .14 & $2.20 *$ & \multirow{4}{*}{$26.22 * * *$} & \multirow{4}{*}{.24} \\
\hline & Regulation of emotion & .20 & .05 & .24 & $4.07 * * *$ & & \\
\hline & Self-emotion appraisal & .19 & .05 & .19 & $3.45^{* *}$ & & \\
\hline & Others'emotion appraisal & .03 & .05 & .04 & .67 & & \\
\hline \multirow{4}{*}{$\begin{array}{c}\text { Extra-role } \\
\text { customer service }\end{array}$} & Use of emotion & .21 & .06 & .24 & $3.62 * * *$ & \multirow{4}{*}{$20.43^{* * *}$} & \multirow{4}{*}{.19} \\
\hline & Regulation of emotion & .19 & .06 & .21 & $3.44 * * *$ & & \\
\hline & Self-emotion appraisal & .01 & .06 & .01 & .22 & & \\
\hline & Others'emotion appraisal & .07 & .06 & .07 & 1.25 & & \\
\hline
\end{tabular}

$*_{p}<.05, * * p<.01, * * * p<.001$

( $\beta=.19, t=3.45, P<.01)$, 자기감정활용 $(\beta=.14, t=2.20$, $P<.05)$ 이 높을수록 친사회적 행동의 동료와의 협력 이 높아지는 것으로 나타났다. 이러한 결과는 판매 원이 자신의 감정을 잘 추스르고 통제할 수 있는 능력을 높게 소지하고, 자신의 감정을 잘 알고 조 절하여 활용하는 능력이 높을수록 동료를 자발적 으로 돕는 협력행동을 더 많이 하는 것을 의미한다.

다음으로, 판매원의 감정지능 차원의 자기감정활 용 $(\beta=.24, t=3.62, P<.001)$ 과 자기감정조절 $(\beta=.21$, $t=3.44, P<.01)$ 이 높을수록 친사회적 행동의 규정 이상의 고객서비스가 높아지는 것으로 나타났다. 이 는 판매원이 그들의 주 업무인 고객대면 상황에서 는 스스로가 자신이 능력 있는 사람이라고 일깨우 고, 설정한 목표를 이루기 위해 최선을 다하며 자 신의 감정을 상황에 맞게 잘 조절하는 능력이 뛰어 나다고 인지할수록 고객에게 규정 이상의 서비스 를 더 많이 제공한다는 것을 의미한다.

이와 같은 결과는 감정지능이 높은 판매원일수 록 판매상황에서 고객에게 긍정적인 감정을 더 잘 표현하고, 고객과 상호작용하는 과정에서 고객을 이 해하고 배려하는 친소비자 행동이 높아진다고 밝힌 $\operatorname{Kim}(2010)$ 의 연구결과와 일맥상통한다. 결과적으 로 판매원의 감정지능이 친사회적 행동에 영향을 미칠 것이라는 가설 3 은 부분적으로 지지되었다.

4. The effect of emotional dissonance on prosocial behavior mediated emotional intelligence
판매원의 감정부조화가 감정지능을 매개하여 친 사회적 행동에 영향을 미칠 것이라는 가설 4 를 검 증하기 위해 경로분석을 실시한 결과는 〈Fig. 1〉과 같이 나타났다.

판매원의 감정지능 $(-.240)$ 과 친사회적 행동 $(-.119)$ 에 대한 감정부조화의 직접효과는 유의한 $(p<.001$, $p<.05)$ 것으로 나타났으며, 친사회적 행동에 대한 감정지능의 직접효과 $(.510)$ 역시 유의한 $(p<.001)$ 것 으로 파악되었다. 이러한 결과는 판매원의 감정부 조화와 감정지능이 각각 친사회적 행동에 유의한 영향을 미치는 변인이라는 것과 판매원의 감정부 조화가 친사회적 행동에 미치는 영향력(-.119)보 다는 판매원의 감정지능이 친사회적 행동에 미치 는 영향력(.510)이 더 크다는 것을 의미한다.

다음으로, 판매원의 감정부조화가 감정지능을 매개 하여 친사회적 행동에 미친 간접효과 $(-.240 \times .510=$ $-.122)$ 는 직접효과 $(-.119)$ 보다 더 큰 것으로 나타 났다. 이러한 결과는 판매원이 직무수행 중 상사나 동료 및 고객으로 인해 경험하게 되는 감정부조화

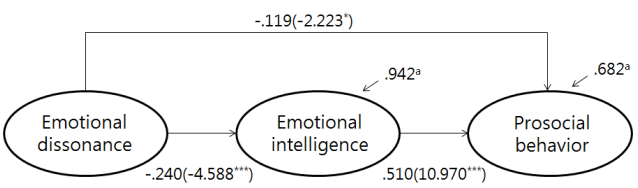

( )은 $t$ 값임, a: 잔여분 변량

〈Fig. 1〉 The effects of emotional dissonance on prosocial behavior mediated emotional intelligence 
가 친사회적 행동에 미치는 영향보다 판매원의 감 정지능을 매개하여 친사회적 행동에 미치는 영향 이 더 크다는 것을 의미한다. 이는 판매원이 직무 수행 중 감정부조화를 경험하더라도 그들의 심리 적 자원이라 할 수 있는 감정지능이 이러한 불편한 느낌을 완충작용을 할 가능성이 크다고 밝힌 Giardini and Frese(2006), Kim(2008)의 연구결과와 리더의 행 동유형이 부하의 혁신행동에 미치는 직접적인 영 향보다 감정지능을 매개하여 미치는 영향이 더 크 다고 밝힌 Ryu and Yoo(2008)의 연구결과를 지지 한다. 결과적으로 판매원의 감정부조화는 감정지능 을 매개하여 친사회적 행동에 영향을 미칠 것이라 는 가설 4 는 지지되었다.

\section{Conclusion}

본 연구는 백화점 패션제품 판매원을 대상으로 판매원이 자신의 역할을 수행하면서 조직구성원 또 는 고객과의 빈번한 상호작용 과정에서 겪게 되는 감정부조화와 판매원의 감정지능이 각각 그의 친 사회적 행동에 영향을 미치는가와 이 변인들 간 인 과관계가 존재하는가를 규명하고자 하였다.

본 연구의 결과를 요약하면 다음과 같다.

첫째, 판매원의 감정부조화는 대조직 감정부조화 와 대고객 감정부조화라는 2 개 차원으로 분류되었 고, 친사회적 행동은 동료와의 협력과 규정 이상의 고객서비스라는 2 개 차원으로 분류되었다. 대조직 감정부조화가 높을수록 동료와의 협력은 낮아지는 것으로 나타난 반면, 대고객 감정부조화는 높을수 록 동료와의 협력이 높아지는 것으로 나타났다.

둘째, 판매원의 감정지능은 자기감정활용, 자기 감정조절, 자기감정인식 및 타인감정인식이라는 4 개 차원으로 분류되었다. 판매원의 대조직 감정부 조화가 높을수록 감정지능의 자기감정활용, 자기감 정인식 및 타인감정인식이 낮아지는 것으로 나타 난 반면, 판매원의 대고객 감정부조화는 감정지능 의 어떠한 차원에도 통계적으로 유의한 영향을 미 치지 않은 것으로 나타났다.

셋째, 감정지능의 자기감정활용, 자기감정조절 및 자기감정인식이 높을수록 친사회적 행동의 동료와 의 협력이 높아지는 것으로 나타났으며, 감정지능
의 자기감정활용과 자기감정조절이 높을수록 친사 회적 행동의 규정 이상의 고객서비스가 높아지는 것으로 나타났다.

넷째, 판매원의 감정부조화가 친사회적 행동에 미 치는 직접효과보다 판매원의 감정지능을 매개로한 간접효과가 더 큰 것으로 나타났다.

이상과 같은 연구결과에 따른 시사점은 다음과 같다.

첫째, 백화점은 판매원이 조직이나 고객으로 인 해 경험하게 될 감정부조화 상태를 줄이기 위해 조 직구성원을 위한 심리상담센터 설치 또는 멘토링 제도 등을 시행할 필요가 있다. 둘째, 백화점 관리 자는 까다롭거나 무리한 요구를 하는 고객들에게 무조건 고개를 숙이고 응대하도록 지시하기에 앞 서, 판매원이 스스로 감정을 조절하고 통제하여 자 발적으로 고객과 조직에 대해 관계지향적인 행동 을 할 수 있는 대안을 마련해야 할 것이다. 예컨대, 고객으로부터의 판매원에 대한 불만이 제기되었을 때 그에 따른 처벌을 가하기 전에 그 경위와 시비 를 가려 소명할 수 있는 기회를 제공할 수 있는 내 부절차가 필요해 보인다. 셋째, 백화점은 판매원이 고객응대나 조직적응에 있어서 어려움에 처했을 때에 자기감정을 이성적으로 통제할 수 있는 방법 을 모색해야 하며, 판매원 교육에서도 판매원의 감 정을 무시한 채 판매지식만을 강조할 것이 아니라, 인간적으로 판매원의 감정을 배려한 훈련프로그램 이 개발되어야 할 것이다. 예컨대, 정기적으로 고객 뿐 아니라, 조직구성원으로 하여금 친절하고 유능 한 판매원을 선정하게 하여 그에 따른 적절한 보상 을 제공함으로써 판매원이 스스로 자신의 감정을 조절하여 감정부조화 상태를 완화하고, 고객과 조 직을 위해 협력하고자 하는 동기를 유발시킬 필요 가 있다.

본 연구의 의의는 백화점 패션제품 판매원을 대 상으로 하여 감정부조화와 감정지능이 친사회적 행동에 미치는 영향을 실증했다는 데에 있으며, 특 히 패션제품 판매원이 경험하는 감정부조화가 선 행연구에서처럼 고객으로 부터가 아니라, 오히려 판 매원이 소속되어 있는 조직, 즉 상사나 동료로부터 야기된다는 것을 밝혔다는 데에 의의가 있다. 그러 나 백화점이라는 유통업태의 패션제품 판매원만을 
대상으로 했다는 점에서 이 결과를 다른 유통업태 의 패션제품 판매원에게 일반화하는 데에는 한계 가 있다. 따라서 앞으로 다양한 형태의 패션 유통 업태에 종사하는 판매원의 감정과 행동에 관한 연 구 및 유통업태 간의 비교 연구가 필요하다. 또한 판매원이 소속되어 있는 조직의 근무 여건에 따라 감정부조화 및 친사회적 행동이 달라질 수 있다는 점에서 조직공정성과 조직신뢰 등과 같은 조직 차 원의 변인과 친사회적 행동과의 관련성에 관한 연 구도 필요할 것으로 사료된다.

\section{References}

Abraham, R.(1999). The impact of emotional dissonance on organizational commitment and intention to turnover. The Journal of Psychology, 133(4), 441-455.

Betterncourt, L. A., \& Brown, S. B.(1997). Contact employees: Relationship among workplace fairness, job satisfaction and prosocial service behaviors. Journal of Retailing, 73(1), 39-61.

Brief, A. R., \& Motowidlo, S. J.(1986). Prosocial organizational behaviors. Academy of Management Review, 11(4), 710-725.

Cho, T. H.(2012, July 16). "Smile, but depressing" Emotional laborers suffer from emotional labor. YTN. Retrieved July 16, 2012, from http://search. ytn.co.kr/ytn/view.php?s_mcd=0102\&key $=20120$ $7160537133661 \& q=\% \mathrm{EC} \% 9 \mathrm{~B}$

Choo, H. J., Kim, H. S., \& Jun, D. G.(2010). The effect of salesperson's affectivity and the performance stressor on emotional labor at the department stores. Journal of Korea Society of Clothing and Textiles, 34(3), 411-423.

Giardini, A., \& Frese, M.(2006). Reducing the negative effects of emotion work in service occupations: Emotional competence as a psychological resource. Journal of Occupational Health Psychology, 11(1), 63-75.

Goleman, D.(1995). Emotional intelligence. New York: Bantam.
Humphrey, R. H., Pollack, J. M., \& Hawver, T.(2008). Leading whit emotional labor. Journal of Managerial Psychology, 23(2), 151-168.

Jung, H. W., \& Kim, C. H.(2006). An empirical study on the effect of emotional intelligence on innovative behavior: The moderating effects of transformational leadership and transactional leadership. Korean Academy of Organization and Management, 30(4), 29-61.

Kang, J. A., \& Lee, Y. J.(2012). A study on the relationships among emotional labor, job satisfaction and turnover intention of beauty industry professionals. The Journal of the Costume Culture, 20(5), 664-678.

Kim, D. H., Ahn, K. H., \& Yoo, C. J.(2012). Customer service strategy at Lotte Department Store. Journal of Consumer Studies, 23(2), 383-397.

Kim, M. S.(2013, May 16). The distribution industry focus on remodeling the store for customer satisfaction in Cheonbook. Dominnews. Retrieved May 16, 2013, from http://www.domin.co.kr/news/ articleView.html?idxno=982719

Kim, S. H.(2008). Relationship between salespersons' emotional dissonance and salespersons' psychological and behavioral responses: Focusing on the moderating effect of emotional intelligence and social support. Journal of Marketing, 37(4), 989-1038.

Kim, S. H.(2010). Can salesperson's emotional intelligence make a customer happy?: Integrated approach in the internal marketing and the external marketing. Journal of Marketing, 39(6), 1585-1621.

Lee, H. E., \& Kim, H. C.(2012). The impact of perceived jaycustomer's behavior on customer contact service employees'emotions and prosocical service behavior intentions: Moderating effects of selfmonitoring and locus of control. Journal of Korea Service Management Society, 13(3), 147-173.

Lee, H. R., Park, Y. J., \& Kwon, K. J.(2010). The effects of chain restaurant employees' organization cohesiveness on interdependence and prosocial 
service behavior. Journal of Hotel Administration, 19(2), 171-189.

Lee, J. R., \& Lee, K. K.(2006). The effect of airline employees'psychological empowerment on job satisfaction, organizational commitment and prosocial behavior. Journal of Hospitality and Tourism Studies, 8(3), 147-161.

Lee, K. B., \& Chung, M. S.(2008). The effect of fashion product salesperson's emotional labor, self-efficacy and burnout on customer-oriented selling behavior. The Journal of the Costume Culture, 16(1), 33-47.

Lee, S. H., \& Kim. G. H.(2012). The qualitative study on the emotional labor of fashion sales personnel: Focused on fast fashion sales personnel. Journal of Korea Society of Clothing and Textiles, 36(5), 534-548.

Lee, Y. K.(2001). The impact of customers'perceived prosocial behaviors of customer-contact employees on the evaluation of service quality, customer satisfaction and customer voluntary performance. Korea Marketing Review, 16(3), 105-125.

Middleton, D. R.(1989). Emotional style: The cultural ordering of emotions. Ethos, 17(2), 187-201.

Morris, J. A., \& Feldman, D. C.(1996). The dimensions, antecedents, and consequences of emotional labor. Academy of Management Review, 21(4), 986-1010.

Park, D. H., Nam, J, H., \& Lee, Y. K.(2002). The structural relationships among antecedents of prosocial behaviors in the hotel food and beverage departments. Journal of Hotel Administration, 11(2), 55-74.

Park, H. J., \& Yoo, T. Y.(2006). The effects of emotional intelligence on subordinate's attitude and performance: Focus on mediating effect of transformational leadership. Korean Journal of Industrial and Organizational Psychology, 19(2), 125147.

Park, J. H.(2013, May 14). Excessive service surveillance 'Big burden'. Ilyonews. Retrieved May 14, 2013, from http://ilyo.co.kr/?ac=article_view\&entry_ $\mathrm{id}=55167$
Park, S. E.(2008). An empirical study on the relationships among employees' perceived display rule demands, emotional dissonance, and their psychological responses. Korea Academy of Organization and Management, 32(1), 25-53.

Park, S. E.(2009). The effects of emotional dissonance on the employee's job attitudes and the moderating role of job autonomy and social supports. Journal of Marketing, 38(2), 379-405.

Park, S. E., \& Woo, J. H.(2010). The effects of leader's emotional dissonance subordinate's attitude and performance: Focus on mediating effect of transformational leadership. Korean Journal of Industrial and Organizational Psychology, 19(2), 125-147.

Rafaeli, A., \& Sutton, R.(1987). Expression of emotion as part of the work role. Academy of Management Review, 12(1), 23-37.

Ryu, Y. Y., \& Yoo, M. B.(2008). The mediating effects of leader's emotional intelligence on the relationships between transformational $\cdot$ transactional leadership and innovative behavior. Korean Public Administration Review, 42(4), 151-177.

Salovey, P., \& Mayer, J. D.(1990). Emotional intelligence. Imagination, Cognition and Personality, 9(3), 185-211.

Shin, K. H., Hahn, S. Y., Kim, W. S., \& Kim, W. H.(2008). Emotional labor and job burnout and job engagement: The moderating effect of emotional intelligence. Korean Journal of Industrial and Organizational Psychology, 21(3), 475-491.

Spencer, S., \& Rupp, D. E.(2009). Angry, guilty and conflicted: Injustice toward coworkers heightens emotional labor through cognitive and emotional mechanisms. Journal of Applied Psychology, 94(2), 429-444.

The Korea Chamber of Commerce and Industry(2013). 2013 Retail data and statistics. Seoul: The Korea Chamber of Commerce and Industry.

Van Dijk, P. A., \& Kirk-Brown, A.(2006). Emotional labour and negative job outcomes: An evaluation of the mediating role of emotional dissonance. 
Journal of Management and Organization, 12(2), 101-115.

Wong, C., \& Law, K. S.(2002). The effects of leader and follower emotional intelligence on performance and attitude: An exploratory study. The
Leadership Quarterly, 13(3), 243-274.

Yoon, M. H., \& Park, J. J.(2005). Perceived exchange relationships of service employees and its impact on in-role/extra-role behavior performance. Journal of Marketing, 34(3), 783-813. 